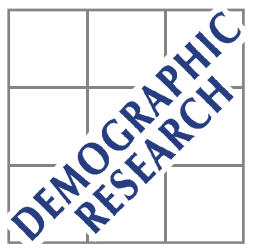

Demographic Research a free, expedited, online journal of peer-reviewed research and commentary in the population sciences published by the Max Planck Institute for Demographic Research Konrad-Zuse Str. 1, D-18057 Rostock · GERMANY www.demographic-research.org

DEMOGRAPHIC RESEARCH

SPECIAL COLLECTION 2, ARTICLE 1

PUBLISHED 16 APRIL 2004, PAGES 1-10

www.demographic-research.org/special/2/1/

DOI: 10.4054/DemRes.2004.S2.1

Reflexion

\title{
Introduction to the Special Collection of papers on "Determinants of Diverging Trends in Mortality"
}

\author{
Vladimir M. Shkolnikov
}

The papers in this special collection were presented at the seminar "Determinants of Diverging Trends in Mortality", held at MPIDR, Rostock on 19-21 of June, 2002. The seminar was organized by the Max Planck Institute for Demographic Research and the Committee on Emerging Health Threats of the International Union for the Scientific Study of Population.

(C) 2004 Max-Planck-Gesellschaft. 


\section{Table of Contents}

1 Background 2

2 Scientific agenda of the seminar $\quad 4$

3 Summary of "Special Collection" studies 5

References 9 
Reflexion

\title{
Introduction to the Special Collection of papers on "Determinants of Diverging Trends in Mortality"
}

\author{
Vladimir M. Shkolnikov ${ }^{1}$
}

\begin{abstract}
This article introduces the Special Collection of papers presented at the first seminar of the Committee on Emerging Health Threats (CEHT) of the International Union for the Scientific Study of Population (IUSSP), "Determinants of Diverging Trends of Mortality". The seminar was held in Rostock (Germany) on 19-21 of June 2002. The seminar encouraged studies on adverse mortality trends and widening mortality differentials between and within countries. The introduction to the collection argues that mortality divergence is a new and significant phenomenon in global population health. It then presents the scientific agenda of the seminar and provides a brief overview of the thirteen studies that constitute the Special Collection.
\end{abstract}

Max Planck Institute for Demographic Research, Konrad Zuse Strasse 1, 18057 Rostock,

Germany. E-mail: Shkolnikov@demogr.mpg.de 


\section{Background}

Declining mortality has long been routinely expected in most countries throughout the world, aside from short-term mortality increases due to wars. Until the 1990s almost all forecasts envisaged global convergence to low mortality over the coming decades. In the 1970s and the 1980s, the global projections of the UN Population Division assumed a gain in life expectancy at birth of 2.5 years every five calendar years for countries with a life expectancy below age 62, after which the gain would decrease to about two years (UN, 1977).

From the beginning of the $20^{\text {th }}$ century to the mid-1960s mortality declined throughout the world. This decline was steeper in countries with higher starting levels of mortality. In addition, mortality trends were remarkably neutral in respect to economic shocks (Demeny, 1965), including the Great Depression of 1929-33.

The general expectation of convergence arose from these mortality trends and forecasts and from systematic analyses of twentieth century mortality data until the mid-1960s. The key studies by A. Omran (1971) and S. H. Preston (1976) provided a viable system of views on the nature of mortality transition and its major determinants. The authors considered continuous reduction in premature mortality, associated with socioeconomic progress, as a progressive sequence of mortality structures, defined in terms of age and cause of death. In the course of transition, the number of deaths from infectious disease at young ages rapidly declines resulting in greater survival to old age and to an increasing burden of chronic (or "degenerative") diseases. It was expected that the progress would be greater in developing countries. This is because they have a greater stock of mortality from infectious disease that is curable by improvements in nutrition and sanitary standards and by relatively simple medical means. Improving nutrition and general wealth, the diffusion of life standards and innovations made by the developed world were expected to accelerate this favorable change. At the same time, less progress was expected in low-mortality countries destined to fight cardiovascular diseases and cancers.

Not surprisingly, in the 1970s many demographers expected continuous progress and future mortality convergence. However, at this very moment although not then known, mortality was increasing in the former Soviet Union and stagnating in Eastern Europe, marking the beginning of unprecedented and long-term mortality reversal. This deviance from the general regularity of continuous mortality decline demonstrated that certain combinations of socioeconomic and sociopsychological conditions with epidemiological patterns may cause significant mortality reversals in national populations.

Further studies of the adverse trends in the Eastern European region have shown that circulatory diseases, accidents and violence, alcohol-related conditions, lung cancer 
and other man-made diseases at ages between 25 and 65 played a decisive role in mortality increase. (Meslé et al., 1999).

Patterns of excess adult mortality from the causes of death similar to those in Eastern Europe were also found in disadvantaged population groups of western countries (Leon, 2001). During the 1980s and 1990s socioeconomic differences in mortality widened in most of the developed countries (Whitehead and Diderichsen, 1997, Mackenbach et al., 2003).

In the 1970s infectious disease was seemingly kept in control. In the late 1980s, however, the spread of premature mortality from HIV/AIDS created a major mortality setback in Sub-Saharan Africa. In the southern and south-eastern part of the region the estimated life expectancy has returned to the levels characteristic of the 1950-1960s, while the probability of death at ages 15 to 55 has risen to roughly $50 \%$ by the late 1990s (UNAIDS, 2000). Other major infections, such as malaria and TB, contributed significantly to the overall toll of premature deaths in Africa. Malaria is one of the likely reasons for the recent life expectancy declines seen in several West African countries that are affected less by HIV/AIDS such as the Ivory Coast, Burkina Faso, Sierra Leone, and Liberia.

In addition, in several African countries the general health situation very much deteriorated as a result of collective violence (Rwanda and Angola) or major socioeconomic disruptions (Zimbabwe and Kenya).

Apart from Africa and the former Soviet Union, North Korea, the Bahamas, Haiti, Honduras, Fiji, Dominican Republic, and Iraq have experienced decreases in life expectancy at birth.

According to the UN Population Division, in 2001 life expectancy at birth was lower than that in 1960 in 7 countries, in 26 and 40 countries it was lower than in 1980 and 1990 respectively (McMichael et al., 2004, Caselli, Vallin, Meslé, 2002).

It is important to mention here that most of the mortality reversals of the 19801990s were primarily related to excess mortality of adults rather than the traditionally vulnerable groups of children and the elderly. This implies that the modern health crises are connected with behavioral, sociopsychological and sociocultural factors and their societal determinants.

At the same time, life expectancy at birth has been continuously increasing in most of the Asian and Latin American countries, supporting the continued increase in the world's average length of life.

Finally, during the 1980s and 1990s western countries made spectacular advances in the reduction of mortality from cardiovascular disease at old ages and reached very high levels of longevity (Oeppen and Vaupel, 2002). This progress hardly could have been expected in the 1970s and was not foreseen by the classic Omran theory. 
The emerging contrast between populations experiencing mortality declines and those experiencing mortality reversals have resulted in an upturn in the global amount of inter-country diversity in the length of life (Moser et al., 2004).

\section{Scientific agenda of the seminar}

A recognition of the phenomenon of mortality divergence between and within countries largely inspired the first seminar of the Committee on Emerging Health Threats held by the International Union for Scientific Study of Population and entitled "Determinants of Diverging Mortality Trends"(see http://www.iussp.org/Activities/thr-index.php) The seminar aimed at studying determinants of unfavorable mortality trends and intercountry and within-country mortality inequalities. It provided a forum for the presentation of theoretical and empirical results on a variety of relevant demographic, epidemiological, and public health issues. Scientific contributions and discussions focused on exceptions from the general pathway of epidemiological transition, relations between population health and sustainable development, mortality reversals in Eastern Europe and other regions, the role of health care systems, and socioeconomic and regional inequalities in mortality in developed and developing countries.

The seminar took place in Rostock (Germany) between 19 and 21 June 2002 and consisted of ten sessions:

Session 1. Pathways of health transition in a changing world.

Session 2. Determinants of unfavorable mortality trends in Central and Eastern Europe.

Session 3. Mortality trends after the fall of communism: country case-studies.

Session 4. Health policies: adequacy of response to health crises.

Session 5. Diverging trends in health transition in the South: country and regional case-studies.

Session 6, 7. Increasing socioeconomic inequalities in mortality within countries.

Session 8. Loci of high mortality in metropolitan areas: contextual and socioeconomic factors.

Session 9. Diverging regional trends in mortality within countries.

Session 10. Trends in mortality inequalities at old age.

Overall, 31 scientific papers were presented. Most of them can be accessed at: http://www.demogr.mpg.de/cgi-bin/publications/list.plx?listtype=14\&workshopid=10. The Special Collection includes a total of thirteen of these papers. 


\section{Summary of "Special Collection" studies}

The first paper by Jacques Vallin and France Meslé examines a variety of mortality trends in developed and developing countries. It shows that Omran's theory of epidemiological transition does not address the mortality reversals seen in Eastern Europe and sub-Saharan Africa. The authors therefore argue in favor of a new theoretical framework that is better supported by empirical evidence. Following J. Frenk et al. (1991), they introduce the concept of health transition, with Omran's epidemiological transition being the first stage.

The next three studies analyze mortality trends in Eastern Europe and the former Soviet Union and identify the driving forces behind observed temporal changes. The paper by France Meslé presents mortality trends in many countries of this region during the last thirty years. From the mid-1960s to the late 1980s all countries experienced similar and unfavorable mortality trends due to rising mortality at adult age. However, in the 1990s these trends began to diverge in different parts of the region due to significant life expectancy increases in Central and Eastern Europe and continuous life expectancy decreases in the former Soviet Union. The two contrasting trends were decomposed by causes of death, suggesting some causal mechanisms for the health crisis.

The paper by Vladimir Shkolnikov and colleagues looks at circumstances of premature deaths of working-age men in Russia in the 1990s. The authors performed an epidemiological case-control analysis of micro-data on deaths of men aged 20 to 55 in Udmurt Republic in Russia. The findings reveal significant independent and combined mortality impacts of education, marital status, unemployment, smoking, and alcohol consumption on mortality from cardiovascular and external causes. The study provides evidence of premature cardiovascular death associated with heavy drinking..

Jitka Rychtaříková studies the recent mortality downturn in the Czech Republic and examines potential explanatory factors. She considers trends in life expectancy and mortality by age and principal causes of death between 1985 and 2000. Analyses of sociodemographic differentials in mortality reduction and the consideration of temporal changes in conventional risk factors and in the production of medical services helps us to understand the nature of recent mortality reduction. Most of the evidence suggests that medical care improvements are likely to play a major role in the favorable change.

The next two studies continue this line of argument by analyzing and discussing the role of health care systems in Eastern European mortality. The paper by Ellen Nolte and colleagues examines contributions of medicine to the increase in life expectancy in West Germany and its stagnation or limited improvements in Lithuania, Hungary, and Romania in the 1980s and the 1990s. Analyses rely on the concept of avoidable causes of death or causes that can be reduced to very low levels by medical treatment or 
prevention. Impact estimations of this group of causes as well as of ischeamic heart disease, and residual causes of death on changes in temporary life expectancies within the 0-74 range show that avoidable causes explain one quarter to one third of the gap between West Germany and Eastern European countries. Reductions in mortality from avoidable causes have produced considerable increases in life expectancy in all countries except Romania. These increases were substantial in the 1980s in West Germany and in Hungary and became significant in Lithuania only in the late 1990s.

Martin McKee and Ellen Nolte discuss health care reforms in Eastern Europe and the former Soviet Union of the 1990s. In all countries of the region various forms of health insurance have replaced the initial Soviet model of centralized state health care. These changes were driven by ideological and economic reasons with no attention given to consequences for the populations' health. This argument is supported by examples of substantial increases in mortality from diabetes and a lack of progress in the fight against some other treatable diseases. Finally, the authors propose a framework for the organization of health care based on the goal of health gain.

The following five studies look at various aspects of mortality differentials within western populations. The first paper by John Lynch and colleagues contributes to the literature on relative income inequality as a factor of excess mortality. The income inequality argument used to be especially strong in studies based on US data due to a consistent cross-sectional association between mortality and income inequality among the US regions. The paper extends earlier analyses by examining mortality at lowerlevel territorial units within the US economic regions and by analyzing 30-year US regional mortality trends in cause-specific mortality and 100-year trends in heart disease and infant mortality. In light of their findings, the link between mortality and income inequality looks to be more complex than suggested by the earlier crosssectional analyses. Determinants of regional differentials in mortality may differ from determinants of temporal mortality changes and both groups of explanatory variables may be dominated by factors other than income inequality.

The paper by Anton Kunst and colleagues describes changes in socioeconomic inequalities in European mortality from the 1980s to the 1990s. It also highlights several data problems of monitoring mortality inequalities. In most of the European countries under study, the relative inter-group differences have increased, while the absolute mortality differences have remained about the same. Data problems often impede an accurate measurement of inter-group inequalities and an assessment of their trends. Series of country-examples show that the use of 'unlinked' data on deaths and populations at risk, changes in social class schemes, and the exclusion of economically inactive people result in biased estimates of inequalities and their changes over time.

The paper by Irma Elo and Greg Drevenstedt investigates causes of death that widen the gap in adult-age mortality between black and white men in the USA. The gap 
increased from 1960 to 1967, declined from 1968 to 1983 and rose again from 1984 to 1995. Sets of causes of death producing a greater impact on the black-white mortality gap differ over time reflecting changes in the patterns of contemporary health threats. The last unfortunate reversal in the decline of the black-white disparity was mostly due to increase in mortality from HIV/AIDS and homicide among black men aged 15 to 39. The authors also discuss socioeconomic and medical care factors of this trend.

The paper by Emmanualle Cambois estimates socioeconomic differentials in mortality in France at ages 65 to 75 for the 1969-73 and 1990-1994 periods by using cohort follow-up data linked to the censuses of 1954 and 1975. The study shows that sociooccupational mortality differentials continue after retirement. These differentials are stable in time, with some increase in disparity between the extremes of the sociooccupational scale. Further analyses suggest a relation between mortality differentials by occupation and by educational status. A particular effect originates from increasing selectivity of low education due to growing average levels of education.

Tapani Valkonen, Pekka Martikainen and Jenni Blomgren provide a quantitative description of a new phenomenon: increasing excess mortality among unmarried elderly people. The study uses data on mortality by age and marital status from 10 industrialized countries for the measurement of mortality changes by marital status among people aged 65 to 74 between the early 70s and mid-90s. It clearly demonstrates that the absolute mortality excess for unmarried elderly people has increased in all countries under study except Japan.

The last two studies of the Special Collection are devoted to mortality inequalities within developing countries. The paper by Alberto Minujin and Enrique Delamonica analyzes trends in average levels and socioeconomic differentials in under-five mortality in 24 countries, using Demographic and Health Survey data. The relative mortality inequality is measured by the ratio of under-five mortality values of lower and upper quintiles of the household distribution by wealth. In a large majority of countries, the relative gap in under-five mortality between rich and poor households increased in the 1990s due to a steeper mortality decrease among the rich and a relative or even absolute lack of progress among the poor. The authors in addition analyze the connection between mortality inequalities and inequalities in immunization and nutritional status.

The paper by Narayan Sastry examines the evolution of intra-urban and urbanrural differences in under-five mortality in the São Paolo region on the basis of microdata from the Brazilian censuses of 1970, 1980, and 1991. During the 20-year period, the average level of under-five mortality decreased, along with the socioeconomic disparity in under-five mortality across households. At the same time, intra-urban and urban-rural differences did not change significantly. The analysis highlights especially disadvantaged health situations of households in poor urban suburbs. 
To conclude, the Special Collection presents a set of highly informative and insightful studies, documenting the global phenomenon of mortality divergence. It would be an interesting reading for researchers and students alike working in the fields of medical demography, epidemiology, and public health. 
Demographic Research - Special Collection 2: Article 1

-- Determinants of Diverging Trends in Mortality --

\section{References}

Caselli, G, Meslé, F, Vallin, J. 2002. Epidemiologic transition theory exceptions. Genus, LVIII (1): 9-51.

Demeny, P. 1965. Investment allocation and population growth. Demography, 2, pp. 203-232.

Frenk, J., Bobadilla J.L., Stern C., Frejka, T. and R. Lozano. 1991. Elements for a theory of the health transition, Health Transition Review, 1(1): 21-38.

Leon, D.A. 2001. Common threads: underlying components of inequalities in mortality between and within countries. In: Poverty, Inequality, and Health ed. by D.A.Leon and G.Walt, Oxford University Press, pp. 58-87.

Mackenbach, J.P., Bos, V., Andersen, O., et al. 2003. Widening socioeconomic inequalities in six Western European countries. International Journal of Epidemiology, 32: 830-837.

McMichael, A.J., McKee, M., Shkolnikov, V.M., Valkonen, T. 2004. Mortality Trends and Setbacks: Global Convergence - or Divergence? The Lancet (in press)

Meslé, F., Vallin, J. and V. Shkolnikov. 1999. "Reversal of mortality decline: the case of contemporary Russia", World Health Statistics Quarterly, 51(2-3-4): 191-206.

Moser, K., Shkolnikov, V., Leon, D. 1994. Mortality of the world's population 19502000: divergence replaces convergence from the late 1980s. Paper presented at the IUSSP seminar "HIV, the Resurgent Infections, and Population Change in Africa", Ouagadougou, 12-14 February.

Oeppen, J. and Vaupel, J.W. 2002. Broken limits to life expectancy. Science, 296(2002)5570: 1029-1031.

Omran, A.R. 1971. The epidemiological transition. Millbank Memorial Fund Quarterly, 49:509-538.

Preston, S.H. 1976. Mortality patterns in national populations. NY, Academic Press.

UNAIDS 2000. Report on the global HIV/AIDS epidemic. June 2000. UNAIDS/WHO.

United Nations. 1977. World Population Prospects as Assessed in 1973. UN, NY, pp. $10-11$.

Whitehead, M., Diderichsen, F. 1997. International evidence on social inequalities in health. In: F.Drever and M.Whitehead eds. Health Inequalities : Decennial Supplement. London, The Stationary Office, pp. 45-69. 
Demographic Research - Special Collection 2: Article 1

-- Determinants of Diverging Trends in Mortality -- 